Tropical Journal of Pharmaceutical Research May 2019; 18 (5): 1089-1094

ISSN: 1596-5996 (print); 1596-9827 (electronic)

(1) Pharmacotherapy Group, Faculty of Pharmacy, University of Benin, Benin City, 300001 Nigeria.

\title{
Effect of solvent fractions of crude extract of Liushenqu on gastrointestinal motility in guinea pigs, and the underlying mechanism(s)
}

\author{
Hongling Zhang ${ }^{1}$, Hairong Zeng ${ }^{1}$, Ling Wang ${ }^{1}$, Yi Qin ${ }^{1}$, Qinwan Huang ${ }^{1 \star}$, Jilin \\ Sun ${ }^{2}$, Renchuan Yao ${ }^{2}$ \\ ${ }^{1}$ Chengdu University of Traditional Chinese Medicine, Chengdu 611137, ${ }^{2}$ Sichuan Fuzheng Pharmaceutical Co. Ltd, Chengdu \\ 610041, PR China
}

*For correspondence: Email: hqwan2163@163.com; Tel: +8613982199974

Sent for review: 28 November 2018

Revised accepted: 23 April 2019

\begin{abstract}
Purpose: To study the effect of solvent fractions of the crude extract of liushenqu on gastrointestinal motility in guinea pigs, and the mechanism of action.

Methods: The effects of solvent fractions of crude extract of liushenqu (LSQ) on receptors in guinea pig isolated small intestinal cells were determined by treatment with different receptor blockers, including diphenhydramine $(0.067 \mathrm{mg} / \mathrm{mL})$, atropine sulfate $(0.064 \mathrm{mg} / \mathrm{mL})$, propranolol hydrochloride $(0.033 \mathrm{mg} / \mathrm{mL})$, phentolamine mesylate $(0.04 \mathrm{mg} / \mathrm{mL})$ and ondansetron hydrochloride $(0.048 \mathrm{mg} / \mathrm{mL})$, to investigate the possible pharmacological mechanism of action.

Results: There was no significant change in the maximum amplitude of muscle tension before and after administration in the control group, petroleum ether fraction group, and dichlormethane fraction group, while muscle tension in the $95 \%$ ethanol and $n$-butanol fractions significantly increased $(p<0.01)$. The mean changes in tension were significantly different from that of control group $(p<0.01)$, but ethyl acetate fraction showed significant intestinal muscle inhibition $(p<0.01)$. Addition of $L S Q$ did not alleviate the inhibition caused by diphenhydramine, but it significantly reversed the inhibition caused by blockers of cholinergic muscarinic receptor, adrenergic alpha- and beta- receptors, and 5-HT receptor ( $p$ $<0.01$ ).

Conclusion: These results indicate that $n$-butanol fraction is the most effective bioactive fraction of $L S Q$, while ethyl acetate fraction has the opposite effect. In addition, its mechanism of action is related to increase in the amplitude of small intestine smooth muscle contraction and acceleration of small intestine peristalsis.
\end{abstract}

Keywords: Liushenqu, Intestinal muscle, Gastrointestinal motility, Mechanism of action

This is an Open Access article that uses a fund-ing model which does not charge readers or their institutions for access and distributed under the terms of the Creative Commons Attribution License (http://creativecommons.org/licenses/by/4.0) and the Budapest Open Access Initiative (http://www.budapestopenaccessinitiative.org/read), which permit unrestricted use, distribution, and reproduction in any medium, provided the original work is properly credited.

Tropical Journal of Pharmaceutical Research is indexed by Science Citation Index (SciSearch), Scopus, International Pharmaceutical Abstract, Chemical Abstracts, Embase, Index Copernicus, EBSCO, African Index Medicus, JournalSeek, Journal Citation Reports/Science Edition, Directory of Open Access Journals (DOAJ), African Journal Online, Bioline International, Open-J-Gate and Pharmacy Abstracts

\section{INTRODUCTION}

Liushenqu (LSQ), also known as Shenqu and Liuqu, is a traditional Chinese medicine for treating indigestion and its related disorders. The main functions of LSQ are related to protection of the spleen and stomach and promotion of digestion, which make it especially suitable for 
formulation of children's food in clinical practice. It is made up of a certain proportion of flour, wheat bran, rice bean powder and bitter apricot seed powder, with water extract of Artemisia annua L., Polygonum barbatum L. and Xanthium sibiricum Patr. Ex Widder, in the ratio of $25: 50: 1: 1: 5: 5: 5$. Usually, it is pressed into a small square with a fixed mold, and fermented under constant temperature of $36{ }^{\circ} \mathrm{C}$ and a humidity of $75 \%[1]$.

Since LSQ promotes digestion and stimulates appetite, it has a wide range of applications in clinical practice, such as treatment of indigestion, stomach pain or bloating, especially for children indigestion and constipation [2]. At present, the mechanism of action of LSQ in promoting digestion is still unclear, but many scholars believe that the digestive enzymes produced during the fermentation process are the medicinal basis of $\mathrm{LSQ}$, and that they can be used as indicators of changes in the fermentation process [3-5].

The aim of the present study was to identify the most biologically active fraction of $L S Q$, as well as its active phytochemical composition, and to determine the mechanism through which it promotes digestion by studying its effect on small intestinal smooth muscle receptors in guinea pigs.

\section{EXPERIMENTAL}

\section{Materials}

The LSQ used in this study was provided by Sichuan Fuzheng Pharmaceutical Co., Ltd., and was identified by Professor Xian-Ming Lu (College of Pharmacy, Chengdu University of Traditional Chinese Medicine, Chengdu, China).

\section{Extract preparation}

LSQ (600 g) was extracted by reflux with $95 \%$ ethanol for $2 \mathrm{~h}$. This was repeated three times, and the filtrates were combined and concentrated to dryness, and re-dissolved in $1000 \mathrm{~mL}$ of water. This was subjected to liquidliquid micro-extraction with different solvents (1000 $\mathrm{mL}$ each) in the order: petroleum ether (60 $\left.-90^{\circ} \mathrm{C}\right)$, dichloromethane, ethyl acetate and $\mathrm{n}$ butanol. Each solvent extract was evaporated and taken up in pure water, made into a drug solution of $0.1 \mathrm{~g} / \mathrm{mL}$.

\section{Animal experiments}

A total of 100 male guinea pigs (five months old, and weighing $250-300 \mathrm{~g}$ ) were obtained from the Sichuan Experimental Animal Center (Chengdu, China). All animals received humane care according to the Declaration of Helsinki promulgated in 1964 and amended in 1996 [6]. All experimental protocols were approved by the Animal Care and Use Committee of Chengdu Municipal Hospital of Traditional Chinese Medicine, Chengdu, China (approval no. SCXK (Chuan) 2013-14).

\section{Preparation and isolation of guinea pig intestinal muscle}

After 7 days of adaptive feeding, the guinea pigs were fasted for $24 \mathrm{~h}$ prior to experimental procedure. The animals were humanely sacrificed via cervical spine dislocation, then laparotomy was quickly carried out. The ileum was cut $10 \mathrm{~cm}$ long, gently rinsed with Krebs solution, and placed in the nutrient solution. The smooth muscle was separated from unwanted tissue and cut into $1.0 \mathrm{~cm}$ long sections for later use [7]. One end of the muscle strip was hung on the bottom hook of a bath containing $30 \mathrm{~mL}$ of Krebs solution, and the other end was tied with an inelastic cotton thread on a muscle tension transducer hook. A load of about $1.0 \mathrm{~g}$ was then applied. All changes in isometric tension were recorded through a force transducer coupled with a bridge amplifier data acquisition system, and the experiment was started after balance was attained [8].

\section{Evaluation of the effect of LSQ extract on isolated intestinal muscles}

The experiment was divided into five groups: control group (CG), ethanol extract group (EEG), petroleum ether group (PEG), dichloromethane group (DIG), ethyl acetate group (EAG) and nbutanol group (n-BG). The bio-signal acquisition system first traced a normal intestinal smooth muscle standard curve. After the contraction was stabilized, $1.5 \mathrm{~mL}$ of $0.1 \mathrm{~g} / \mathrm{mL}$ solution of each solvent fraction was added to the bath separately. For the control group, $1.5 \mathrm{~mL}$ of pure water was used. The intestinal muscle contraction curve was recorded after addition of drug solution. At the end of the experiment, the log file was saved, and the muscle tension was measured within 1 min before the administration $(\mathrm{AA})$, and at the first $1 \mathrm{~min}$ after the administration (AB) using the interval measurement method provided by the bio-signal software. The average tension change value (AV) was calculated as in Eq 1.

$A V=(A A-A B)$ 
Assessment of the effect of LSQ extract on isolated intestinal muscle receptors

The experiment was divided into five groups: diphenhydramine group (DG, $25 \mathrm{mg} / \mathrm{mL}$ ), atropine sulfate group (ASG, $0.024 \mathrm{mg} / \mathrm{mL}$ ), propranolol hydrochloride group (PG, $1 \mathrm{mg} / \mathrm{mL}$ ), phentolamine mesylate group (PMG, $0.8 \mathrm{mg} / \mathrm{mL}$ ) and ondansetron hydrochloride group (OHG, 4.8 $\mathrm{mg} / \mathrm{mL}$ ). The biosignal acquisition system first traced a normal intestinal smooth muscle standard curve. After stabilization of the contraction, the corresponding receptor blocker was added to the bath, and the muscle tension was measured within $1 \mathrm{~min}$ before the administration, and at the $1 \mathrm{~min}$ after the administration using the interval measurement method provided by the bio-signal software. Then, $2 \mathrm{~mL} 0.1 \mathrm{~g} / \mathrm{mL}$ ethanol extract of LSQ was added, and the change in intestinal muscle tension was recorded within $1 \mathrm{~min}$. At the end of the experiment, the log file was saved, and the muscle tension was measured 1 min before the receptor blocker administration (BA), 1 min after the receptor blocker administration (AR), and the first minute after the administration of the LSQ $(\mathrm{BL})$, using the interval measurement method provided by the bio-signal software. The average tension change value (AC) was calculated as indicated in Equation 2.

$A C=(B L-A R)$

\section{Statistical analysis}

Data from animal experiments are expressed as mean \pm standard deviation (SD), and were analyzed using SPSS 21.0 software with single factor analysis of variance between groups. Values of $p<0.05$ were considered significant.

\section{RESULTS}

\section{Effect of different solvent extracts of LSQ on isolated intestinal muscles}

As seen from Table 1, the maximum and amplitude of muscle tension were significantly increased in the ethanol extract $(E E, 5 \mathrm{mg} / \mathrm{mL}$ ) and $n$-butanol groups (n-BG, $5 \mathrm{mg} / \mathrm{mL}$ ), relative to control group $(p<0.01)$. The average tension changes were significantly different from that of the control group $(p<0.01)$. It can be seen from the results that intestinal muscle tension was significantly increased in EE and n-BG groups ( $p$ $<0.01)$. Moreover, the $n$-butanol fraction produced the most significant changes. There was no significant change in the maximum and amplitude of muscle tension before and after administration in petroleum ether group
$(5 \mathrm{mg} / \mathrm{mL})$ and dichloromethane group $(5 \mathrm{mg} / \mathrm{mL})$, and the average change value was not significantly different from that in the control group, indicating that the components of the petroleum ether and dichloromethane had no effect on smooth muscle contraction. The maximum muscle tension before and after administration of ethyl acetate $(5 \mathrm{mg} / \mathrm{mL})$ was significantly reduced $(p<0.01)$, and the amplitude after administration was close to zero, showing a significant inhibitory effect. Thus, there may be substances inhibiting smooth muscle in this fraction. The representative intestinal muscle movement curve of each group is shown in Figure 1.

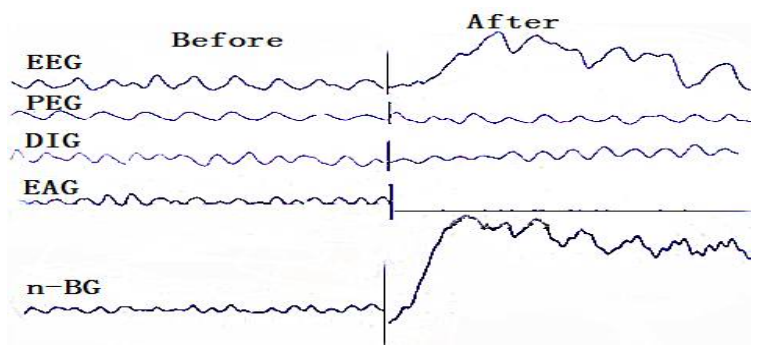

Figure 1: Effect of different solvent extracts of LSQ on isolated intestinal muscles

\section{Effect of LSQ on isolated intestinal muscle receptors}

As shown in Table 2, after the addition of diphenhydramine $(\mathrm{D}, \quad 0.067 \mathrm{mg} / \mathrm{mL})$, atropine sulfate (AS, $\quad 0.064 \mathrm{mg} / \mathrm{mL}$ ), propranolol hydrochloride (PG, $0.033 \mathrm{mg} / \mathrm{mL}$ ), phentolamine mesylate (PM, $0.04 \mathrm{mg} / \mathrm{mL}$ ) and ondansetron hydrochloride $(\mathrm{OH}, \quad 0.048 \mathrm{mg} / \mathrm{mL})$, maximal muscle tension decreased significantly such that the amplitude was close to 0 , and the receptor blocker significantly blocked the smooth muscle contractility $(p<0.01)$. After addition of ethanol extract of LSQ $(6.67 \mathrm{mg} / \mathrm{mL})$, there was no significant change in the indices of diphenhydramine (0.067 $\mathrm{mg} / \mathrm{mL})$ group; the changes in muscle tension in other groups were significant $(p<0.01)$. The changes in intestinal muscle contraction curve before and after of administration for each group are shown in Figure 2.

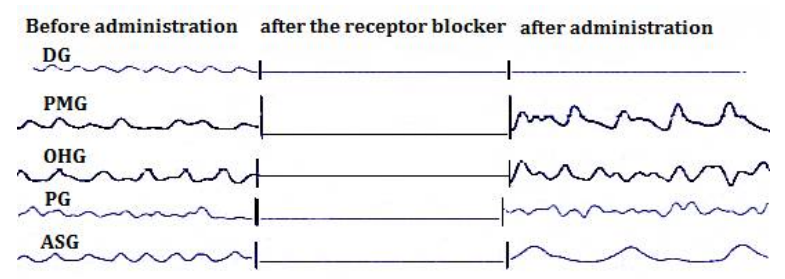

Figure 2: Effect of LSQ solvent fractions on isolated intestinal muscle receptors 
Table 1: Effect of different fractions of $L S Q$ on intestinal muscle tension

\begin{tabular}{|c|c|c|c|c|c|c|}
\hline \multirow{2}{*}{ Fraction } & \multirow{2}{*}{$\begin{array}{l}\text { Concentration } \\
(\mathrm{mg} / \mathrm{mL})\end{array}$} & \multicolumn{2}{|c|}{ Before administration } & \multicolumn{2}{|c|}{ After administration } & \multirow{2}{*}{$\begin{array}{l}\text { Mean tension } \\
\text { change }\end{array}$} \\
\hline & & Maximum & Amplitude & Maximum & Amplitude & \\
\hline Control & 0 & $1.62 \pm 0.13$ & $0.22 \pm 0.09$ & $1.64 \pm 0.15$ & $0.23 \pm 0.09$ & $0.04 \pm 0.03$ \\
\hline $\mathrm{EE}$ & 5 & $1.88 \pm 0.40$ & $0.47 \pm 0.19$ & $7.67 \pm 1.54 \Delta \Delta$ & $4.57 \pm 1.49 \Delta \Delta$ & $2.97 \pm 0.9^{\star \star}$ \\
\hline $\mathrm{PE}$ & 5 & $3.03 \pm 0.28$ & $0.55 \pm 0.22$ & $3.43 \pm 0.66$ & $1.23 \pm 0.64$ & $0.26 \pm 0.16$ \\
\hline DI & 5 & $2.76 \pm 0.22$ & $0.59 \pm 0.21$ & $3.62 \pm 1.55 \Delta$ & $1.19 \pm 0.64$ & $1.08 \pm 0.83$ \\
\hline EA & 5 & $0.29 \pm 0.26$ & $0.83 \pm 0.36$ & $-0.86 \pm 0.4 \Delta \Delta$ & $0.07 \pm 0.03 \Delta \Delta$ & $0.79 \pm 0.35^{\star *}$ \\
\hline$n-B$ & 5 & $0.31 \pm 0.21$ & $0.89 \pm 0.33$ & $6.63 \pm 1.42 \Delta \Delta$ & $6.24 \pm 1.09 \Delta \Delta$ & $4.78 \pm 0.88^{* *}$ \\
\hline
\end{tabular}

EE: ethanol extract group; PE: petroleum ether group; DI: dichloromethane group; EA: ethyl acetate group; $n-B$ : n-butanol group. Data are expressed as mean $\pm S D(n=10) ; \Delta p<0.05, \Delta \Delta P<0.01$, comparison of value before, and value after drug administration in each group; ${ }^{*} p<0.05$, ${ }^{* *} p<0.01$, compared with control group

Table 2: Effect of LSQ on isolated intestinal muscle receptors

\begin{tabular}{lcccccccc}
\hline Fraction & $\begin{array}{c}\text { Dosage } \\
\text { (mg/ml) }\end{array}$ & Maximum & Amplitude & Maximum & Amplitude & Maximum & Amplitude & $\begin{array}{c}\text { Mean } \\
\text { tension } \\
\text { change }\end{array}$ \\
\hline DP & 0.067 & $2.89 \pm 0.40$ & $0.85 \pm 0.33$ & $2.07 \pm 0.31 \Delta \Delta$ & $0.16 \pm 0.05 \Delta \Delta$ & $2.17 \pm 0.37^{\star *}$ & $0.23 \pm 0.11^{* *}$ & $0.05 \pm 0.04$ \\
PM & 0.04 & $0.26 \pm 0.24$ & $0.70 \pm 0.19$ & $-0.43 \pm 0.12 \Delta \Delta$ & $0.15 \pm 0.07 \Delta \Delta$ & $1.42 \pm 0.79^{* *}$ & $1.71 \pm 0.59^{* *}$ & $0.89 \pm 0.48$ \\
AS & 0.064 & $2.14 \pm 0.15$ & $0.57 \pm 0.17$ & $1.57 \pm 0.17 \Delta \Delta$ & $0.11 \pm 0.02 \Delta \Delta$ & $3.87 \pm 1.69^{* *}$ & $2.21 \pm 1.41^{* *}$ & $1.04 \pm 0.96$ \\
OH & 0.048 & $0.07 \pm 0.21$ & $0.73 \pm 0.42$ & $-0.86 \pm 0.36 \Delta \Delta$ & $0.10 \pm 0.06 \Delta \Delta$ & $1.09 \pm 0.82^{* *}$ & $1.81 \pm 0.75^{* *}$ & $1.20 \pm 0.62$ \\
PL & 0.033 & $2.96 \pm 0.42$ & $0.75 \pm 0.56$ & $2.16 \pm 0.32 \Delta \Delta$ & $0.14 \pm 0.07 \Delta$ & $3.10 \pm 0.52^{* *}$ & $0.92 \pm 0.47^{* *}$ & $0.50 \pm 0.25$ \\
\hline
\end{tabular}

DP: diphenhydramine group; PM: phentolamine mesylate group; AS: atropine sulfate group; OH: ondansetron hydrochloride group; PL: propranolol hydrochloride group. Data are expressed as mean $\pm \mathrm{SD}(\mathrm{n}=10) ; \Delta p<0.05$, $\Delta \Delta p<0.01$, comparison before and after addition of receptor blocker in each group; ${ }^{*} p<0.05,{ }^{* \star} p<0.01$, comparison before and after LSQ addition in each group

\section{DISCUSSION}

Traditional Chinese Medicines (TCMs) are considered useful agents for treating various human diseases [9]. In fermented TCM, changes in various conditions during fermentation affect the quality of the finished product [10]. Although the chemical composition and mechanism of action of Liushenqu is still not clear, its significant pharmacological activity means that it will continue to be of use in Chinese medicine. Thus, it is necessary to provide scientific data to serve as a basis for its use in Chinese medicine. The purpose of this study was to investigate the components of LSQ, and to explore its mechanism of action in promoting digestion.

Separation of the components of LSQ with different solvents was carried out according to solvent polarities. The pharmacological activity of lower polarity component was substantially low, and the components having a significant influence on the gastrointestinal contraction were found in the n-butanol fraction. The n-butanol fraction contained presumably saccharide, glycoside or protein, which is consistent with opinion in the literature that digestive enzymes are the main medicinal substances of LSQ [11]. Some scholars have discovered that the effect of LSQ on GIT pharmacology can be improved by high temperature treatment [12]. However, enzyme components are destroyed at high temperatures. This contradiction suggests that there must be a significant class of high temperature-resistant components in LSQ which have significant pharmacological activities. The results of this study suggest that the active principle of LSQ may be present in the $n$-butanol fraction, which lays the foundation for further research on this fraction. It was also observed that the ethyl acetate extract had significant intestinal muscle tone inhibition, which is being reported for the first time.

In addition, the ethyl acetate fraction showed a significant inhibition of intestinal peristalsis. This means that there are chemical components in the LSQ that are antagonistic to digestion. In addition, there may be other pharmacological effects of LSQ, such as antidiarrheal effects.

Receptors are important factors for regulating gastrointestinal motility. Together with the nervous system and gastrointestinal hormones, they participate in the regulation of gastrointestinal motility [13]. At present, it is believed that there are mainly cholinergic muscarinic receptors, adrenergic alpha and beta receptors, 5-HT receptors, histamine receptors and various gastrointestinal hormone receptors in the gastrointestinal tract [14]. In this study, the contraction of the intestinal muscle was blocked using several receptor blockers, and the effects 
of the extract of LSQ was monitored to verify which receptor LSQ acted on.

Histamine receptors are active substances widely distributed in the human body. Diphenhydramine has an anti-histamine $\mathrm{H} 1$ receptor; it has a strong inhibitory effect on the central nervous system, and acts as a $\mathrm{H} 1$ receptor blocker. The experimental results showed that Liushenqu could not reverse the inhibition caused by diphenhydramine, indicating that it does not act on histamine receptors. The parasympathetic nerves that innervate the gastrointestinal tract are mainly from the vagus nerve. The stimulatory effect of the vagus nerve on the gastrointestinal nerve is achieved through choline fibers. Some of the post-ganglionic nerve endings release Ach which causes excitatory effects through the $M$ receptor. In addition, phentolamine mesylate is a short-acting, nonselective a-receptor (a1, a2) blocker, and ondansetron hydrochloride is a selective serotonin 3 (5-HT3). The antagonist propranolol hydrochloride, is a non-selective $\beta$-blocker that has antagonistic effects on both $\beta 1$ and $\beta 2$ receptors. The experimental results show that LSQ reversed the inhibition of these receptors, indicating that it acts on the four receptors.

Thus, LSQ acts on the cholinergic $M$ receptor, the adrenergic $\alpha$ and $\beta$ receptors, and the $5-\mathrm{HT} 3$ receptor. That is to say, LSQ acts on the cholinergic $M$ receptor, enhances the sympathetic nerve excitation, thereby inducing contraction of the gastrointestinal smooth muscle and increasing the secretion of the digestive gland. It also acts on the adrenal $\alpha$-receptor and B2 receptor, stimulates the small intestine smooth muscle, enhances relaxation of the small intestine, and acts on the 5-HT3 receptor to mediate gastrointestinal contraction and hormone secretion. The total effect is reflected in an increase in the contraction amplitude of the intestinal muscles and an increase in intestinal peristalsis.

\section{CONCLUSION}

The results of this study show that LSQ significantly enhances smooth muscle contraction in the small intestine of guinea pig. Its active principle is concentrated in the n-butanol fraction, while the ethyl acetate fraction has components that inhibit gastrointestinal motility. The mechanism involved in its enhancement of digestion is related to increase in the contraction amplitude of small intestinal smooth muscle and the acceleration of intestinal peristalsis.

\section{DECLARATIONS Acknowledgement}

This study was supported by the Sichuan Provincial Administration of Traditional Chinese Medicine project - Key Technology Breakthrough and Quality Optimization Improvement of Liushenqu Tablets (no. 2018c022).

\section{Conflict of interest}

No conflict of interest is associated with this work.

\section{Contribution of authors}

The authors declare that this work was done by the authors named in this article and all liabilities pertaining to claims relating to the content of this article will be borne by them. All authors have read and approved the manuscript for publication.

\section{Open Access}

This is an Open Access article that uses a funding model which does not charge readers or their institutions for access and distributed under the terms of the Creative Commons Attribution License (http://creativecommons.org/licenses/by/ 4.0) and the Budapest Open Access Initiative (http://www.budapestopenaccessinitiative.org/rea d), which permit unrestricted use, distribution, and reproduction in any medium, provided the original work is properly credited.

\section{REFERENCES}

1. Ren QL, Song XX. Analysis of the Quality of Liushenqu. Chin J Mod Drug Appl 2010; 4: 113-114.

2. Lin JM, Huang SP, Kuang Y, Yu SY. Analysis on Medication Reguarity of Professor YU Shao-yuan in Treating Irritable Bowel Syndrome. Guid J Tradit Chin Med Pharm 2018; 24: 41-43.

3. $X u Y$, Zheng L, Xiang $H Y$, Xiang $H Y$, Zhu $H L$, Xie $Q H$. Dynamic analysis of five digestive enzymes during the fermentation of Liushenqu. Chin Brew 2012; 31: 43.

4. Liu TF, Jia TZ, Gao H, Liu XY, Wu Y. Investigation on the ratio of ingredients in the preparation process of Divine Comedy. Chin Med Mat 2014; 20: 40-43.

5. Wang LF, Gao WY, Pei XP, Liu HX, Pei MR. Dynamic detection and analysis of digestive enzyme activity in fresh dried products and different methods of Liu Diqu. Chin J Exp Tradit Med Form 2017; 23: 20- 24.

6. World Medical Organization. Declaration of Helsinki. BM 1996; 313: 1448-1449. 
7. Yu P, Fei Y, Li HP. Evaluation of the effect of bran frying process on the efficacy of Atractylodes macrocephala $L$. Chin J Tradit Chin Med 2017; 35: 1091-1093.

8. Carbone SE, Wattchow DA, Spencer NJ, Hibberd TJ, Brookes SJH. Damage from dissection is associated with reduced neuro-musclar transmission and gap junction coupling between circular muscle cells of guinea pig ileum, in vitro. Front Physiol 2014; 5: 319.

9. Peng $W$, Shen $H$, Lin B, Han P, Li CH, Zhang QY, Ye BZ, Rahman K, Xin HL, Qin LP, Han T. Docking study and antiosteoporosis effects of a dibenzylbutane lignan isolated from Litsea cubeba targeting Cathepsin $K$ and MEK1. Med Chem Res 2018; 27: 2062-2070.

10. Yu JY, Li Y, Wang DX, Shi XY. Isolation of Fermentation Strains and Study on Pure Fermentation of Liushenqu. Chin J Exp Tradit Med Form 2013; 19: 12-14.
11. Huang GN. Discussion on the detection and quality standards of digestive enzymes in the songs such as Divine Comedy. Chin Tradit Pat Med 1981;5: 18-19.

12. Zhang N, Han SY, Zhang YS. Research on the quality standard of Liu Diqu. J Tradit Chin Med 2015; 30: 100.

13. Choi KH, Jeong SI, Lee JH, Hwang B S, Kim S J, Lee S, Choi B K, Jung $K Y$. Pharmacological mechanism responsible for the Atractylodes japonica induced distalcolonic contraction in rat. Phytom Int $J$ Phytother Phytopharm 2011; 18: 408-413.

14. Karaki $H$, Ikeda M. Effects of external calcium and some metabolic inhibitors onbarium-induced tension changes in guinea pig taenia coli, Japan J pharm 1967; 17: 603612. 